\title{
13 Collaboratively Cleaning, Archiving and Curating the Heritage of the Future
}

\author{
ADAM DRAZIN, ROBERT KNOWLES, ISABEL BREDENBRÖKER \\ AND ANAIS BLOCH
}

\section{Introducing Bauhaus Cleaning}

In the anthropological project, an installation called 'Cleaning Up After Gropius', which we outline here, we examined cultures of cleaning and archiving at the Bauhaus in Dessau, and the legacy of that site's extraordinary design heritage for contemporary work. ${ }^{1}$ Design work always happens in the wake of previous design, and should ask how it is that people work everyday with a pre-designed world to manipulate change, transformation and stasis. We suggest that anthropology can contribute to the formation and clarification of design issues through critical ethnographies of design politics in which futures do not belong exclusively to design and designers (Suchman 2011). This can help designers to wrestle with what we will call the 'problems of the future', meaning confronting the problematic 'otherness' of futures, to locate their own approach to design futures among multiple approaches, and to identify with modes of change.

The Bauhaus in Dessau is one of the sites of the very origins of modernist design. In the 1920s, the professors at the Bauhaus in Dessau made a film, How We Live in a Healthy and Economical Way, which showcased their household designs and enacted the kind of modern lifestyle they envisaged. In the film, a maid, and Walter and Ise Gropius, demonstrate cooking, cleaning, relaxing and entertaining using a range of new household equipment. During periods of the film, the maid mops, does washing up and tidies throughout the striking modernist rooms of their new houses, the Meisterhäuser. In 2015, the Bauhaus Dessau Foundation re-evoked the theme of the household in the Haushaltsmesse 2015 (Household Exhibition), entitled On the Art of Housekeeping in the Twenty-First Century and curated by Regina Bittner and Elke Krasny. The curators invited a range of designers, artists, architects and anthropologists (ourselves) to present work in the grounds of the Meisterhäuser, considering the question 'how can we live in a healthy and economical way?' In the intervening period, between 1927 and 2015, many of the designs in the film have become globally common, indicative of a normative conception of a modernist 
lifestyle, while the houses themselves have become a UNESCO World Heritage monument to celebrate their archetypal contribution to human culture through design.

As anthropologists, with a particular interest in material culture, we set out to develop site-based ethnographic work, with a view to observing and interpreting the cultural dimensions and tensions of the household. Spending time in the Meisterhäuser and related buildings, we quickly observed that this is a wonderful place to research cleaning, which is frequent, regular and careful. This being a heritage site, cleaning and tourism are at the heart of daily activity while many other activities (such as cooking) are constrained or forbidden. Research into cleaning made us aware that, in order to understand how it was being done, we also had to understand the wider heritage environment. How these sites are treated has been the subject of intense political debate in the past, and cleaning practices and skills also happen in parallel with the management and archiving of heritage objects and materials. We use the word archiving to refer to the management of collections, involving acquisition, research, preservation, storage and some display work. By contrast, we are using the word curation to refer to the assemblage of material (some from collections) for display. Following the ethnographic research, we developed an installation using the data gathered. The installation aimed to confront designers with the creativity of cleaning in making heritage, and to present a range of ways in which people every day in the Bauhaus sites work with the material world with one eye on the future. A design-interested audience might then locate themselves within this cultural ecosystem of futures.

Our argument draws on several ideas. In the Dessau Bauhaus, people who clean feel powerfully engaged in a project of value-creation, and are a part of wider design debates about how to mobilize the Bauhaus traditions for a better future through design. Cleaning happens as a part of multiple paradigms of action to shape and socialize the material world (including archiving, curating and design). It involves imagination, value-creation and social commitment to a collective project.

Dessau, however, also illustrates multiple futures. The town is littered with past materializations of visions of the future, and these gradually decaying concrete forms (decaying unless preserved through cleaning and archiving work) are humanized and socialized. They carry with them the accretive traces of human life and inhabitation, as Øye (2007) calls it, a homeliness in the 'feeling for grey'. The tensions in Dessau, in which people in many different positions and vocations must consider what is to be removed (i.e. is dirt), what is to be actively cleaned (i.e. is heritage) and what is to be left, involve the negotiation of multiple materializations and projects of futures. When we talk about the 'otherness' of futures, we mean how working collaboratively comprises a situation which itself has implications for the cultural conception of futures: that is, other people have previously materialized or objectified futures; they have done so with multiple purposes, skills and modes of behaviour; and there is a palpable issue in this heritage situation of when one feels able to physically engage with material forms and substances. Otherness can here be thought of as

\section{Design Anthropological Futures}


concerning the ways that conceptualizations of culture and of self involve objectification (Miller 1987), and also the politics of futures as the experience of sameness and difference (Appadurai 2013). One of the points of comparison between cleaning and design is the sense of working with sameness and difference to produce new arrangements of meaning; another is the ways in which a person feels equipped to engage. In cleaning, the categorization of parts of the world as 'dirt' is convergent with an embodied legitimation and compulsion to act on physical matter.

Artistic installations and re-presentations of ethnographic work, for designinterested audiences, should aim to help designers locate themselves within multiple site-based paradigms of change; and also help designers to think about their own bodily understandings of legitimately working with the material world, through evoking a sense of contextual immersion in a site (Wright 2010).

We argue then for more anthropological approaches, which consider futures in terms of encounters with externalized problems or otherness (Rosenberg and Harding 2005; Suchman 2011) rather than as expressionism (i.e. futures as made or imagined; see Ingold 2012; Yelavich and Adams 2014), and which present these problems and encounters to design audiences. This is an argument that is especially appropriate for heritage design, but may also be appropriate elsewhere.

This chapter proceeds with a brief description of the final installation, followed by two key parts. We outline Dessau as a site, the thinking, which led us towards material cultures, and cleaning, and some moments from our ethnographic work. Secondly, we consider the thinking behind the resulting installation. The chapter finishes with some comments on the implications for collaborative issue formation in design anthropology.

\section{'Cleaning Up After Gropius': a Brief Description}

The installation 'Cleaning Up After Gropius' was exhibited in several parts, each one making use of data and media in slightly different ways. The first part of the exhibit was sound-based, using three different soundtracks to explore cultures of cleaning. On entry to the house, standing on the staircase, one hears the sound of the mopping of Bauhaus spaces, with the distinctive echo of the concrete interiors. Intercut with these sounds are extracts of interviews with a cleaner, who outlines the techniques, materials and planning of what is involved. The intention is that the audience gains a sense of the collective work which has produced this particular banal environment; a staircase which otherwise remains unquestioned and selfevident. As such, the recordings make present in the imagination an absent cleaner.

Moving downstairs, the audience enters those basement spaces where cleaning and laundry work were once done out of sight of the main residential part of the house. In one relatively bare room, with steel pipes tracking across the ceiling, a much wider range of sounds of cleaning can be heard, including people talking about and organizing cleaning. An absence of things to look at forces attention to the sounds of people elsewhere discussing what to use, instructing one another or 
agreeing on a course of action. This soundtrack is intended to help the audience to imagine cleaning as a social event, and comprising a variety of cultures of household cleaning.

Entering the largest room in the basement, the audience encounters two other parts to the installation; a video and a display of 'dirt for auction'. In the corner, a massive, original concrete and steel washtub is built into the fabric of the house. On the walls are the hooks from which drying laundry lines could criss-cross the room. Here, a video plays on a loop. It presents people cleaning and washing in a modernist-style kitchen, doing the washing up, wiping down surfaces, sweeping the floor, and it sets these clips to repetitive classical music (rather than using research recordings, like the sound installations). The bodily actions of cleaning are often repeated, in time with the musical rhythms, going over spots and surfaces again and again, wiping then wiping again as if honing with a cloth the already-cleaned surface. As someone scrubs a pan with circular swipes, we hear the sawing of a violin, as if they are playing the pan. These bodily repetitions are supposed to evoke the embodied knowledges and craft of cleaning. After each twenty or thirty seconds of balletic musical cleaning, the audience then sees a video shot of Meisterhäuser interiors or exteriors, dwelling on the surfaces of the walls, windows and shelves. The cleaning sequences become faster and build towards a crescendo. Ultimately, the video ends fading to a black and white 1920s image of this Meisterhaus: Gropius' own vision of it.

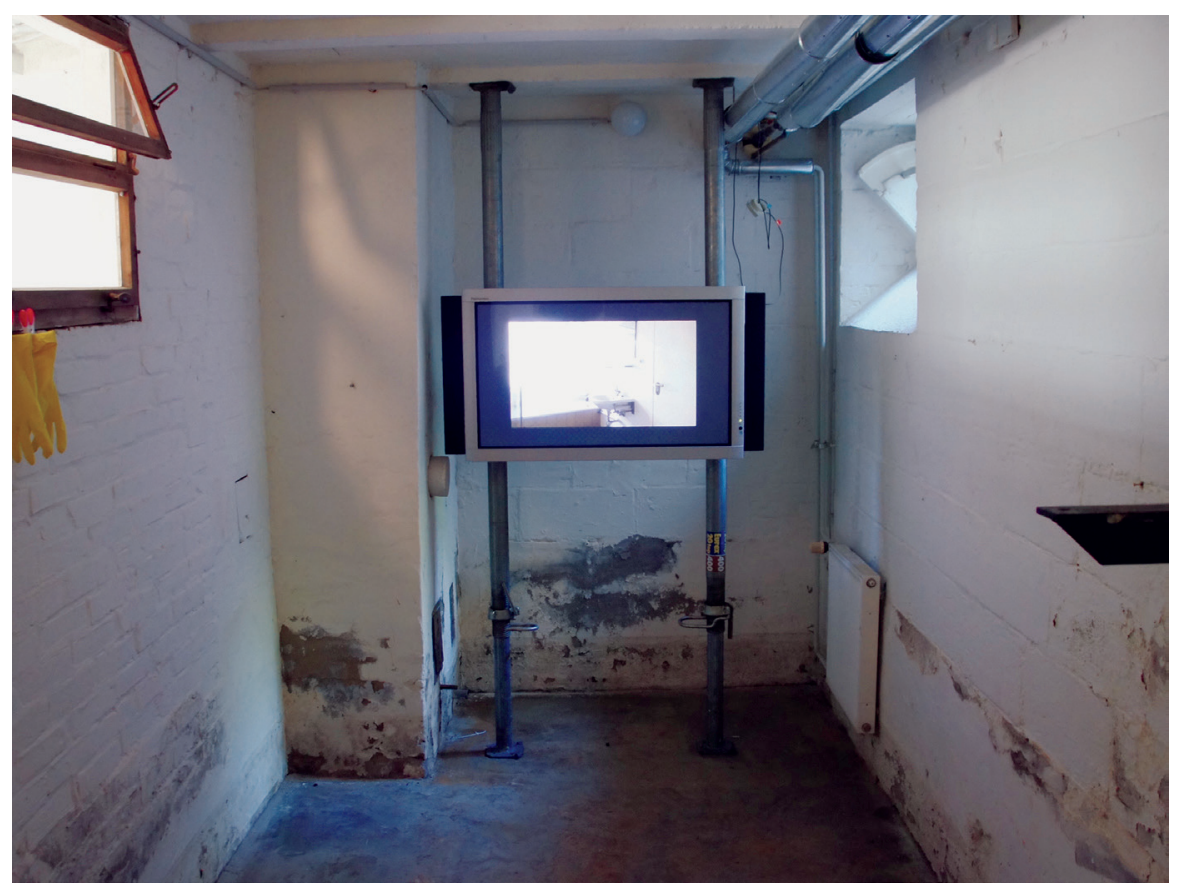

Figure 13.1 The Video Installation in 'Cleaning Up After Gropius' (c) Adam Drazin

\section{Design Anthropological Futures}


If this video does its intended job, by the end a viewer may begin to see the surfaces of the Meisterhaus differently. Even the view from a window is not 'given', but has largely been produced by cleaning. We may thus begin to see the glass behind the view, and we may recognize how the image of our 'heritage' has itself been created by accretive cleaning. In this way, this video concerns the idea of cleaning as a creative act, which involves not only the disposal of dirt but the making of form, and potentially of value.

The last part of the installation consists of a display of Bauhaus dirt (Bauhaus Schmutzes), with associated notices saying it is to be auctioned. The dirt hangs in small sealed plastic bags from washing lines, selected by colour and form, and presented under lights. Some of the dirt is produced by the cleaning of the Meisterhaus, some is sourced from the site of the Bauhaus archives where the collections are kept and where archivists must often decide what objects or materials are to be preserved, cleaned or (sometimes) thrown away. Some of the dirt (the cheaper pieces) has been mixed with material from less important Dessau sites. These bags represent material categorized as unvalued 'dirt' by cleaners or archivists, consciously or unconsciously.

As a whole, these three parts of the installation - audio, video and collected dirt - explore different cultural dimensions of ways in which people on the Bauhaus site engage with futures, by re-presenting mostly contextual data from anthropological research. In the remainder of this chapter, we talk through the work process and thinking that underlies it. We will proceed by examining different approaches to the collaborative formation of issues, and what Dessau as a site can contribute to them.

\section{Collaborative Approaches to Design Futures in Dessau}

In recent years, the question of the formation of issues in user-centred design has been closely linked to cultural discussions of futures (e.g. Ehn, Nilsson and Topgaard 2014). Earlier debates around whether design work may be problem-focused or a reflexive learning process (Bannon and Ehn 2013), have been superseded by debates about the clear constitution of design issues, and how material things manifest or represent them. Design anthropological work has firstly problematized the clear separation of design questions from solutions, which often appear convergently (Binder et al. 2011), such that to address design issues, one must often pay more attention to design futures. Secondly, the idea that design provides a material response to an absence or gap, such as a need or demand, has also been challenged. Instead of dialogues of material and immaterial phenomena, design anthropology increasingly sees itself as conducting work through transformations of concrete material forms or artefacts (e.g. Halse 2013; Wallace 2012; Drazin 2013). As a site, Dessau has a particular contribution to make here because it is itself a grand proposal for a design solution, a future and a reinvention of modern living.

One powerful expression of the paradoxes of issue-formation is the concept of 'design things' (Binder et al. 2011), which characterizes the specific materialities of 
design work (used for conceptualizing, prototyping and demonstrating design) as particular kinds of emergent things. Thomas Binder et al. here develop the observation that the word 'thing' across Northern Europe used to mean a gathering of people or meeting, often of a political kind, but has come to also mean a physical object. Likewise, the meaning of the word 'matter' is binaristic, implying both what is (politically) significant - for example, a problem - but also meaning physical substance.

How can we as designers work, live and act in a public that involves a heterogeneity of perspectives and actors to engage in alignments of their conflicting objects of design? How can we gather and participate around design things? These things themselves modify the space of interactions and performance, and will be explored as sociomaterial frames for controversies, ready for unexpected use and opening up new ways of thinking and behaving (Binder et al. 2011: 1).

Design problems are generally 'wicked problems' (Buchanan 1992) involving multiple social purposes, perspectives and understandings. It follows that to bring together a gathering of concerned parties may also be a manifestation itself of key design issues, expressed in the spaces and differences between them. Participation in such 'design things' traces the boundary between issue and response, because the conversation about what to do must necessarily involve learning about problems and action from other people's perspectives. As we outline later, this notion is crucial to understanding Dessau, where interaction (and friction) between a multitude of interested parties identifying closely with the site has been productive of emergent design pathways.

When it comes to the anthropological literature on futures and futurity, a different set of tensions emerge. There are many different kinds of anthropological approaches to futures, some design-related (Appadurai 2013; Yelavich and Adams 2014; Faubion, Marcus and Rabinow 2008; Suchman 2011) and some not (Wallman 1992; Fischer 2009). A common consideration of design futures is, however, to see futures as culturally existing through a combination of 'imagination' (Ingold 2012) and 'making' (Yelavich and Adams 2014). As Ingold (2012: 29) comments, although not in precise terms but more as a guideline: 'Let us allow then that design is about imagining the future.'

While both imagination and making are highly significant, we suggest futures necessarily manifest themselves in heterogeneous ways. Dessau, in particular, illustrates how existing material things and places constitute futures, and mobilize consciousness and collaboration. We consider that such material objectifications should be seen as important for cultural consciousness itself (Miller 1987).

The Meisterhäuser site manifests a number of design paradoxes, and its emergent form has been the result of the participatory engagement over many years of diverse stakeholders. Since German re-unification in 1989, it has re-emerged as a hugely symbolic site of national and international design interest. The Bauhaus Dessau Foundation, which controls the site, is committed, within the terms of its

\section{Design Anthropological Futures}


remit as a foundation, to heritage archiving and design education, and works to negotiate the space between the two. Its approach to the site and its running of the Haushaltsmesse have been important parts of how it conducts this negotiation.

Under intense media and public interest and debate for much of the last 25 years about the material details of how to treat its buildings, the site has been pulled between two alternative, and potentially conflicting, directions. One alternative has been to focus on restoration as a 1920s site. The thinking behind this approach would argue that the buildings may be seen as in themselves expressions of principles of design, and that by manifesting these principles one can celebrate, inspire and stimulate design action. The way forward for the site, in this conception, involves material preservation of the Meisterhäuser as heritage.

On the other hand, the material heritage of the late 1920s might be seen as more of a burden than a benefit for design action, since what is important for action are principles and values which can be adapted and applied in new, different circumstances. Dessau is itself considered a city, which needs design attention, having lost its industrial base and experiencing unemployment and emigration. Arguments in this vein have, over the years, emphasized the importance of re-establishing a lively design school in Dessau, and building, changing or re-building using contemporary methods, in order to not only represent design but to practise it. Strong arguments were put forward that the Meisterhäuser should not be renovated, but appreciated effectively as preserved ruins, so as not to risk any confusion with contemporary design, which faces new and different issues and requires new design spaces and forms, not old ones.

The question of how materially to treat the Bauhaus sites and buildings was connected to questions of how to work for a better future for Dessau, and for Germany, through design. The physical buildings have catalysed these questions, representing and demonstrating the ability to envisage, imagine, collaboratively organize and shape the material world in wholly original ways.

After years of stalemate, what has eventually happened is, to an extent, a reconciliation of the two possible alternative modes of action. It was, however, the first argument, the site as heritage, which blazed the trail, which enabled collaborative design work to follow. The site was declared a UNESCO World Heritage Site in 1996, but while the Bauhaus building was preserved, among the Master houses only the Fringier House had been restored at this stage. As the extensive factories in Dessau and the surrounding region closed, and the consequences of the emigration of so many young and middle-aged adults became clear, money was ploughed into engaged social projects in the area. Two more of the buildings were renovated in 1999-2000, and the area was landscaped in 2002. This left the Walter Gropius House, which was perhaps the most symbolic of them but which had been destroyed, to be considered for rebuilding. Long after 2000, as it became clear that social investment was not going to reverse emigration or industrial decline, it was decided that the site should be an architectural park or museum for the public, and this was finally launched in 2014. Having established this site as a heritage park, the 
Bauhaus Dessau Foundation then began to undertake public design exhibitions, and also build the educational capacities of the school. Two of the restored houses were planned as exhibitionary spaces for contemporary design, and design courses began to be expanded in the Bauhaus.

We believe that this site not only stands as a design history icon, but also epitomizes some paradoxical contemporary issues for design practice and its materiality. These include, in particular, the recurring tensions between working to presence and to erase design. When faced with a materialized design vision for the future, does one leave it, preserve it, modify it or erase it? Even if it is possible to express an opinion on this, a significant question remains: under what circumstances can a set of designers actually feel permitted to do something, to be allowed to engage materially?

Our own approach to futures was more informed by material culture than by imagination and making. In this approach, the future is not only being materialized now, but it always has been, producing multiple referents:

This is the paradox of modern futurity: while we are taught to believe in the emptiness of the future, we live in a world saturated by future-consciousness as rich and as full as our consciousness of the past (Rosenberg and Harding 2005: 9).

For us, the study of the future is frequently archaeological, involving attention to material things, which invariably emerge from the past. The world may be littered with material anticipations of futures. The temporal framework of 'past-presentfuture' is inadequate here because, to compare change to a journey, one frequently traces where one has been in order to consider what comes next. Various anthropologists have addressed futures as commonly manifested, encountered, deployed and performing social roles. Wallman (1992) initiated such approaches, while Appadurai (2013) considers 'the future as cultural fact, that is, as a form of difference' (2013: 285). Suchman (2011) presents us with a major critical vision of some of the implications of this pervasiveness of futures. Because some professional groups, including designers, may present themselves as closer to, or owners of, manifest futures, consequently the study of futures can trace lines of power and inequality. In a world of futures, certain people, ideas, practices, groups and material forms become consigned to the past.

In our research, we asked not so much how people in their everyday lives express ideas of the future, but rather how they react to and confront problematic and ubiquitous potential futures. We focused on the material sites of the Dessau Bauhaus, considering how people work with these material sites, creating and removing matter and forms, negotiating the gradients of professional and everyday knowledges and skills. Our focus, then, became not so much how people make futures in response to problems, but how they deal with the problems of the future. We thought of such problems as having at least three interrelated aspects: the issue of the material legacy of past manifestations of possible futures as heritage; the

\section{Design Anthropological Futures}


question of how design change can happen in a site pervaded by prior design; and, lastly, how designers can achieve an engaged stance where they feel enabled to engage with the unfolding archaeology of futures.

\section{Cleaning, Archiving and Value Creation}

As previously mentioned, cleaning and archiving were the main ways in which we observed hands-on engagements with the Meisterhäuser. In a heritage environment, the drive to preserve or erase materialized futures is dealt with on an everyday level by cleaning.

One of our first impressions of the Meisterhäuser, especially the rebuilt Gropius house (by Berlin-based BFM Architects), was that no actual house could really be this clean. The unreal opalescent windows, half like windows, and half like walls, and the stark white walls are intended to communicate the house as a concept as much as a building. These square, concrete surfaces are echoed in familiar buildings in many parts of the world. Severe cleanliness of the exteriors then assists in the recognition both of design, incorporating thing as concept, and of heritage. The buildings are, however, simultaneously special and extremely banal (as familiar forms). Standing in one of the upstairs bathrooms, one could be anywhere in the world, in any house, apartment, hotel or institution. There are white walls, an enclosed bathtub beneath a window, a pedestal sink with mixer taps and a swivelling spout. It takes an act of imagination to remember that this bathroom is the original manifestation of this form, and it is partly because we could be anywhere that cleaning and preservation of this bathroom is so important.

The cleaning of each house, room and location is highly regulated, with careful attention to space, materials and public access. Different schedules (daily, weekly, monthly) may apply, as well as different intensities of cleaning apply (for example, floors might be mopped daily, while skirting boards are wiped only once a month). Contact with surfaces is sometimes regulated, as it is, for instance, forbidden to attach things to walls.

There is, then, something puzzling about the way cleaning mediates the special and the typical on this site. One might have expected cleaning of modernist houses to be globally uniform. A house is a house, the materials are mostly familiar, and there are measurable, quantifiable dimensions to cleaning. But not every modernist house is the same, apparently. These houses are cleaned by a professional company, whose manager details something of their trade, when we asked about a particular house:

Anthropologist: How long does the cleaning take?

Cleaner: About two hours. There are two women who do these houses together and clean them within this timeframe. There's an estimate for the objects and a norm, and then my colleagues are given the expected time.

Anthropologist: What does estimate and norm mean? 
Cleaner: We measure the square metres, then there's a norm per square metre. We estimate how much our colleague is able to finish within the time, and the square metres and norm combined then produce that time. $\ldots$

Cleaner: You can calculate this. It's just that our norm is our - I don't want to say 'business secret' - but they are different from cleaning firm to cleaning firm, so it means we don't reveal the norm.

The cleaning activity is evidently very like a craft. The actions of the cleaners are learned, embodied, repetitive movements with specific tools. The cleaner applies particular pressure, leans into the task to a certain degree, and moves the mop, cloth, vacuum or brush in repeated sweeps of a certain dimension, which cover the surface cleaned over a period of time. 'This is a craft, yes (Gebäuderreinigerhandwerk)', reports the cleaning manager.

Most importantly, many cleaners understand their work as a creative process, which maintains or creates value ('den Wert der Objekte zu erhalten'). In the Bauhaus buildings, value and preservation seem more significant than hygiene or tidiness per se. There is an evident pride in involvement with the site. Cleaning is generally officially a concealed activity, and while it was easy for us to witness cleaning, it was difficult to formally interview cleaners themselves, which indicated boundaries and control around cleaning knowledge. The manager comments, "Clean" means not just washing floors but also preservation of value. This is actually very important... That's where the effort lies in cleaning.'

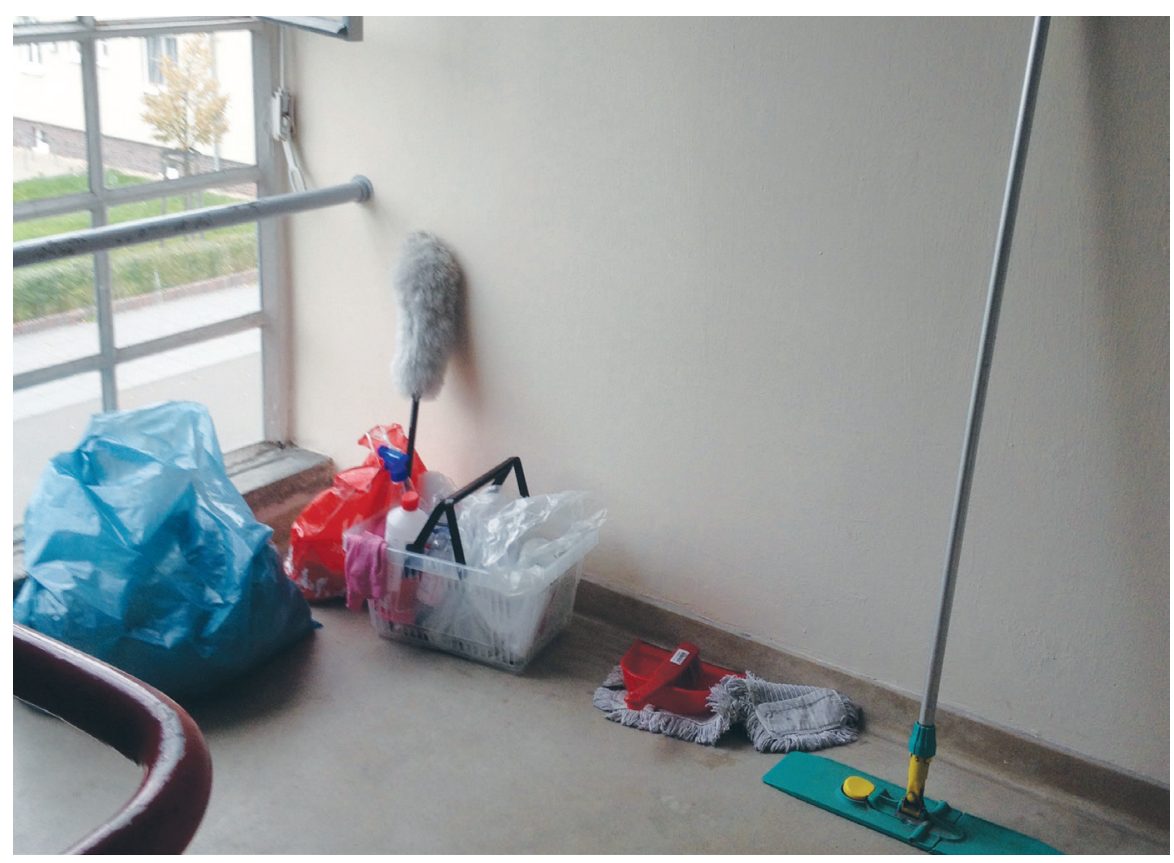

Figure 13.2 Cleaning equipment on a staircase in the Bauhaus building $\subsetneq$ Adam Drazin

\section{Design Anthropological Futures}




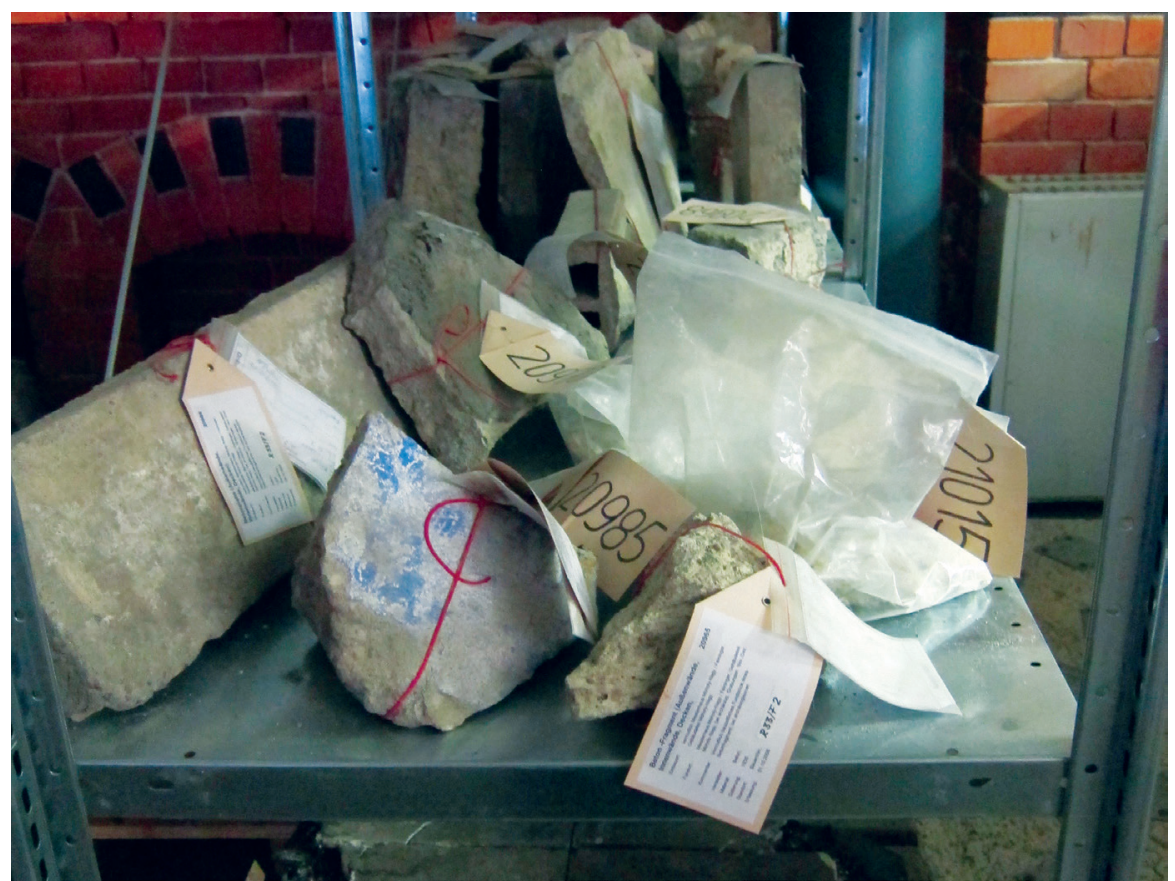

Figure 13.3 Heritage materials in bags in the archive of the Bauhaus collection (c) Adam Drazin

The more we spoke with different people involved in Bauhaus properties, the more comments such as this one began to challenge the paper walls between different professional groups. For example, archivists and cleaners may have very different training, are differently appreciated, but both feel bound up in the bigger project of care for this site, and are actively making decisions about the material heritage. Cleaning and archiving can thus be thought of as parts in a political economy of knowledges in the Bauhaus Dessau Foundation properties.

In the extensive Bauhaus storage facilities, housed in an old disused factory, archivists are faced with two key kinds of decision about their collection. First, they have to decide what to keep or throw away, what is valuable heritage and what is better seen as rubbish. Second, they must decide how things can be preserved. Cleaning might be destructive, for which reason it is better to just leave and store some things so their slow decay is minimized. In this respect, archiving is ascribed a much higher 'pro-active' long-term decision-making value than cleaning, which by contrast is seen as more reactive and immediate in its decision-making.

\section{Re-Presentation, Sensation and Change}

As has been discussed, in Dessau it was wholly unclear whether the 'household of the future' already existed, was being designed, or is yet to be designed. After studying cleaning, we might think of it as the work of stasis, keeping things the same, 
or an ongoing work of change. To put this another way, there was the experience of a tension between the purposes of design heritage and of design practice as modes of social amelioration. We also observed multiple paradigms of action in reaction to these household futures.

These tensions were important for how an installation based on ethnography might be received by a design-interested audience, between a validation of the status quo and a call to redesign cleaning. As design is the 'science of the artificial' (see Cross 1982; Bannon and Ehn 2013), designed objects are, in their essence, collaborative humanized objects. These must entail consideration of prior experiences, knowledges and practices. Our installation aimed to help a design audience to locate themselves and operate within a politicized economy of plural cultural paradigms of material change, including cleaning and archiving. This exercise contains a sense of problematic 'otherness', confronting design with problems of the future in the three senses we have described: the prior material legacy of futures, other paradigms of change and the feeling of an ability to legitimately engage.

How might an audience identify with a sense of material change? The work of anthropologist Inger-Elin Øye in Shwerin, eastern Germany, is helpful here. She talks about the 'feeling for gray', and how senses of dirtiness and cleanliness are about appropriate change. In the 1990s, her informants compared their perceptions of different parts of Germany: 'Despite its less attractive appearance, the eastern environment was described as being more honest, modest, natural, human and innerlich. It was in the east that these people felt zu Hause (at home)' (2007: 114 , emphasis in original). At first, Øye herself saw the slightly decaying, concrete facades of the blocks of Shwerin as being concerned with conformity and sterility. And yet, she writes, 'I came to see how gray walls, with their earth-like colours and their state of deterioration, resembled organic life processes: the development of individual differences, coming of age, and decay. I developed a better feeling for gray' (2007: 121).

Cleanliness and dirtiness, preservation and decay are perceptually relative, and here they are about how change happens and how we identify with it. Either can be seen as more or less about conformity or creativity, sterility or life. Øye's conceptualization of 'feeling for' suggests a personal identification by an anthropologist with senses of change, experienced in an aesthetic encounter with material surfaces. It parallels Wright's (2010) argument that when anthropologists use artistic methods, they can aim to achieve a sense of 'immersion' rather than the conceptual distance of most anthropological texts: 'Why would an artist attempt to immerse you, and an anthropologist attempt to largely extricate you from that experience?' (Wright 2010: 71).

Following the work of these anthropologists, we considered the artistic re-presentation of our ethnographic work on cleaning and archiving as an immersive critical re-location (Suchman 2011) of the design audience. Therefore, the installations we developed comprise exploratory questions, expressed in material form. Sensory variation is an especially important vehicle for doing this.

\section{Design Anthropological Futures}


Our initial sound-based installations are perhaps the most simple. They unpack the work of cleaning and show its value by revealing the difficulties and efforts of cleaning. Counterpoised to the stillness of the grey walls, the sounds and descriptions are in essence a work of de-fetishization of value as manifested in the Meisterhäuser, revealing it to be created by labour. Because the sound comprises conversations, the installation also communicates how cleaning work necessitates collaboration.

As the audience moves to other parts of the installation, the contrasts with the sound installation are intended to open up the range of problems of dealing with futures for designers. In the sound installations, one should feel a bodily reaction and empathy: listening to echoing cleaning sounds, one almost feels the water, senses in one's own body the strokes of the mop and repetitive wiping. By contrast, when interviews with archivists are played in the final part of the installation, there is no feeling of embodiment, as one is simply listening to a set of cerebral decisions.

The video part of our installation poses the problem of different forms of temporality and evaluation in cleaning, and bridges notions of cleaning and heritage. It effectively illustrates the transformation of many, small, quantified moments of skilled cleaning work, to produce transcendent, eternal, Bauhaus heritage. At the same time, it considers some of the contradictions of the visibility of cleaning work. Cleaning eliminates and conceals matter, which is dirt, but also creates surfaces rendered as-new which are perceived as clean. Acts of evaluation are more explicit in the auction of Bauhaus Schmutzes, which present the audience very directly with the question of how they would evaluate individual remnants of past activity and work.

Thus, throughout the exhibition, there is an exploration of which people, and groups of people, have both the legitimate capacity and the collective motivation to clean. While conceptualization of matter as 'dirt' legitimizes physical intervention,

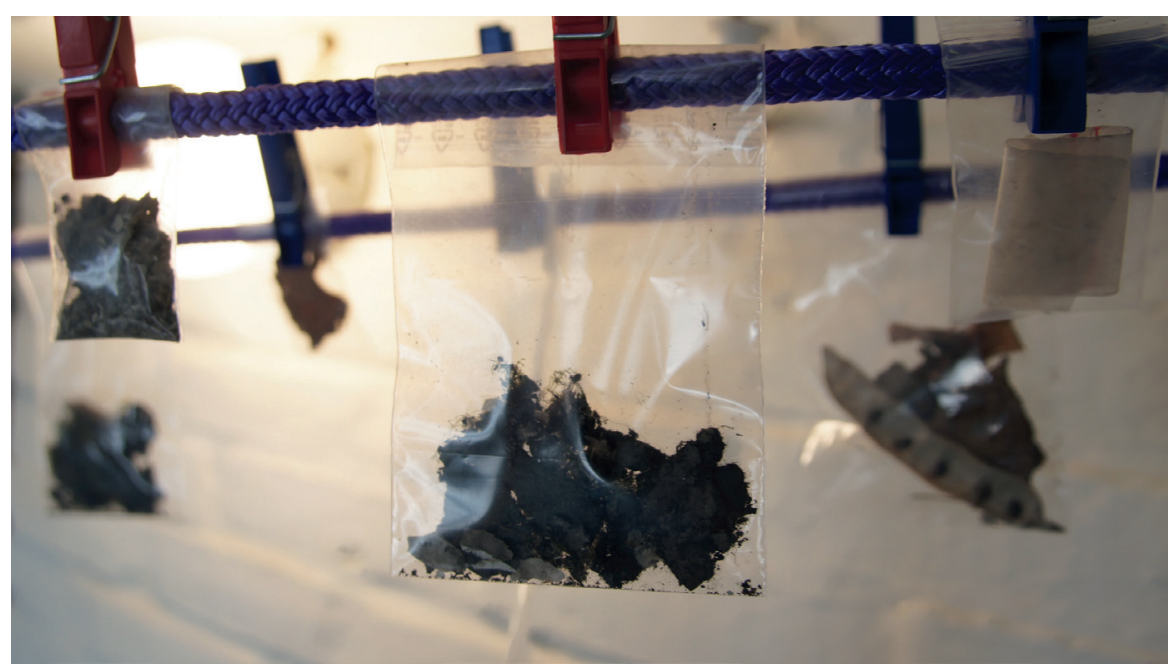

Figure 13.4 Dirt for auction (Bauhaus Schmutzes) in the 'Cleaning Up After Gropius' installation (C) Adam Drazin 
categorization as 'heritage' produces a barrier between matter and audience which may prevent legitimate physical engagement.

Audiences are in effect, we hope, being asked questions by these materialized problems of the future. What paradigms of change do they identify with? How do they evaluate cleaning? And how can they perceive or sense cleaning and dirt in material terms? In our attempt to break up the activities observed into multiple problematics of the future, we anticipate the possibility of multiple kinds of design projects, in which different designers find different 'feelings' for Bauhaus concrete, and try to establish how a project resonates with the different communities in Dessau who are engaging with futures.

\section{The Challenges of Other Futures as Heritage and Dint}

We argue for collaborative issue formation in design anthropology which re-presents ethnographic work, to confront designers with the different kinds of projects and plural futures in which people are engaged in their own lives, and which seeks to draw designers into paradigms of action. Futures are not the preserve of designers, but are pervasive. While any social context involves imaginations, discourses, routines and practices, it is by researching futures through material culture that we can identify interesting key issues through which people experience problematizations of culture (Miller 1987). Convergently with being problematic, material design heritage in a place such as Dessau is a prime motivator of collaborative work, enabling many professional groups and stakeholders to come together and engage in mutual projects. This collaborative focus is possible largely because this material heritage exists as a manifestation of prior knowledges and practices of futures. The material landscape of Dessau should not be dismissed as the past of design (as dirt), but is part of ongoing processual materializations that enable engagements with future possibilities.

To be able to work on this site is an extraordinary opportunity. As we have outlined, the Bauhaus Dessau Foundation has faced a particular, persistent sense of having to choose between 'preservation of the designed past' and 'working for a newly designed future', but has moved to transcend this tension in a range of ways, including using exhibitionary techniques and spaces.

To re-present ethnographic data in design anthropology work is partly to try to evoke similar problems of the future, confronting design work with its potential to become either untouchable heritage or unrooted praxis, and need to recognize existing modes of engagement with futures. Design anthropology can itself be understood as knowledge which is 'situated' (Suchman 2011: 14, citing Haraway 1988), which needs to locate its own project in relation to other situated knowledges through acts of ethnographic re-presentation. The designer's perspective is often raised above others in its validity, yet this can be simultaneously a benefit and a burden. How do we both validate designerly perspectives as potentially progressive, and authorize them in relation to other ways of knowing? An appreciation of values

\section{Design Anthropological Futures}


is a necessary element of contemporary design work (Buchanan 2010), and yet values are expressed not so much in fixed knowledges as in process and transactionality, and we have here shown how value creation is a collaborative project, not the preserve of design paradigms only. An example of legitimate and authorized action would be when the material world is seen as 'dirt', valueless by definition and something to be cleaned; and yet the residue of one person's life and action risks being seen as dirt by another person. Design should collaboratively resonate with many people's perspectives and lives, and hence needs to try to negotiate this difficult territory of living dirt, of value-creation and change, through for example the mutual re-presentation of 'other' projects.

In Cleaning Up After Gropius, we therefore moved from asking about what the design issues of the future household are, to asking how change happens in this site, and how design is created and formed. The evocation of futures inevitably involves senses of fixity and change. Design anthropology's productions appear both to evoke senses of spaces where change may happen, but also to materialize propositions for new futures, which are already beginning to acquire fixity, and will become the heritage of the future, rigorously and professionally preserved and cleaned.

\section{Note}

1 The project title refers to Walter Gropius, the famous architect and pioneer of modernism, who was director of the Bauhaus school from 1919-33.

\section{References}

Appadurai, A. (2013), The Future as Cultural Fact, London: Verso.

Bannon, L. and Ehn, P. (2013), 'Design: Design Matters in Participatory Design', in J. Simonsen and T. Robertson (eds), Routledge Handbook of Participatory Design, 37-63, London: Routledge.

Binder, T., Ehn, P., De Michelis, G., Jaccuci, G., Linde, P. and Wagner, U. (2011), Design Things, Cambridge, MA: MIT Press.

Buchanan, R. (1992), 'Wicked Problems in Design Thinking', Design Issues 8 (2): 5-21.

Buchanan, R. (2010 [1995]), 'Branzi's Dilemma: Design in Contemporary Culture', in R. Buchanan, D. Doordan and V. Margolin (eds), The Designed World: Images, Objects, Environments, 13-27, Oxford: Berg.

Cross, N. (1982), 'Designerly Ways of Knowing', Design Studies 3 (4): 221-7.

Drazin, A. (2013), 'The Social Life of Concepts in Design Anthropology', in W. Gunn, T. Otto and R. C. Smith (eds), Design Anthropology: Theory and Practice, 33-50, London and New York: Bloomsbury.

Ehn, P., Nilsson, E. and Topgaard, R. (eds) (2014), Making Futures: Marginal Notes on Innovation, Design and Democracy, Cambridge, MA: MIT Press.

Faubion, J., Marcus, G. and Rabinow, P. (2008), Designs for an Anthropology of the Contemporary, Durham, NC: Duke University Press.

Fischer, M. (2009), Anthropological Futures, Durham, NC: Duke University Press. 
Halse, J. (2013), 'Ethnographies of the Possible', in W. Gunn, T. Otto and R. C. Smith (eds), Design Anthropology: Theory and Practice, 180-96, London and New York: Bloomsbury. Haraway, D. (1988), 'Situated Knowledges: The Science Question in Feminism and the Privilege of Partial Perspective', Feminist Studies 14: 575-99.

Ingold, T. (2012), 'Introduction: The Perception of the User-Producer', in J. Donovan and W. Gunn (eds), Design and Anthropology, 19-33, Farnham: Ashgate.

Miller, D. (1987), Material Culture and Mass Consumption, London: Routledge

Øye, I. -E. (2007), 'The Feeling for Gray: Aesthetics, Politics, and Shifting German Regimes', Social Analysis, 51 (1): 112-34.

Rosenberg, D. and Harding, S. (eds) (2005), Histories of the Future, Durham, NC: Duke University Press.

Suchman, L. (2011), 'Anthropological Relocations and the Limits of Design', Annual Review of Anthropology, 40: 1-18.

Wallace, J. (2012), 'Emergent Artefacts of Ethnography and Processual Engagements of Design', in W. Gunn and J. Donovan (eds), Design and Anthropology, 207-18, Farnham: Ashgate.

Wallman, S. (ed.) (1992), Contemporary Futures, London: Routledge.

Wright, C. (2010), 'In the Think of It: Notes on Observation and Context', in A. Schneider and

C. Wright (eds), Between Art and Anthropology: Contemporary Ethnographic Practice, Oxford: Berg.

Yelavich, S. and Adams, B. (eds) (2014), Design as Future-Making, London: Bloomsbury.

\section{Design Anthropological Futures}

